\title{
Epulis osteoplastica in a child
}

\author{
Ryo Sasaki $^{1}$, Noboru Takanashi ${ }^{2}$, and Toshihiro Okamoto ${ }^{1}$ \\ ${ }^{1}$ Tokyo Women's Medical University School of Medicine \\ ${ }^{2}$ Affiliation not available
}

August 28, 2020

\begin{abstract}
A 13-year-old female patient presented with a $20 \times 15$-mm pedunculated, elastic hard cauliflower-shaped lesion with a healthy color and partial erosion attached to the maxillary gingiva in the right maxillary first molar region. The lesion gradually grew over a year. Excisional biopsy was performed and histopathological analysis indicated epulis osteoplastica.
\end{abstract}

\section{Hosted file}

Sasaki_epulis_clinicalcasereport.doc available at https://authorea.com/users/354668/articles/ 478139-epulis-osteoplastica-in-a-child 


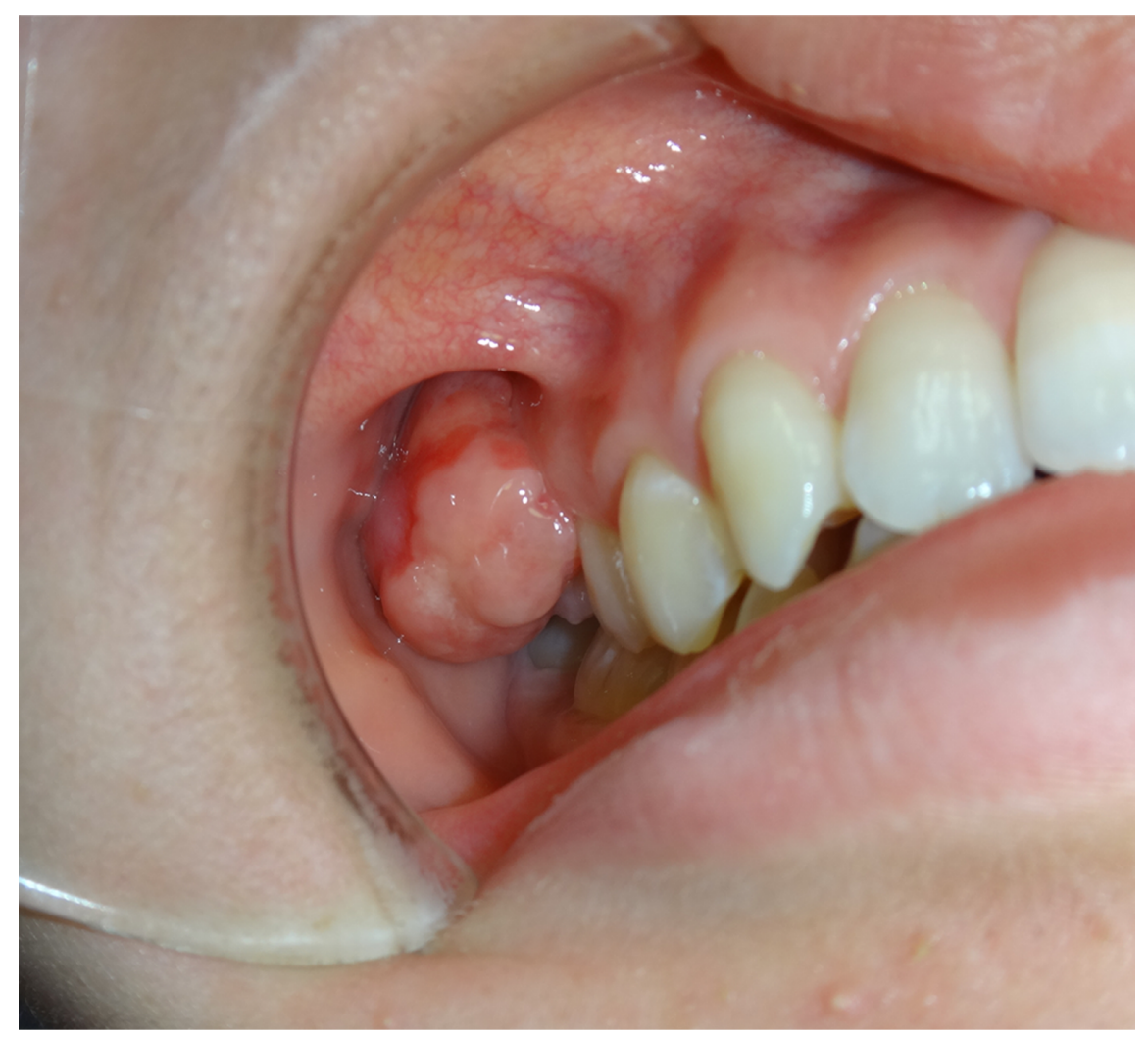

Figure 1 


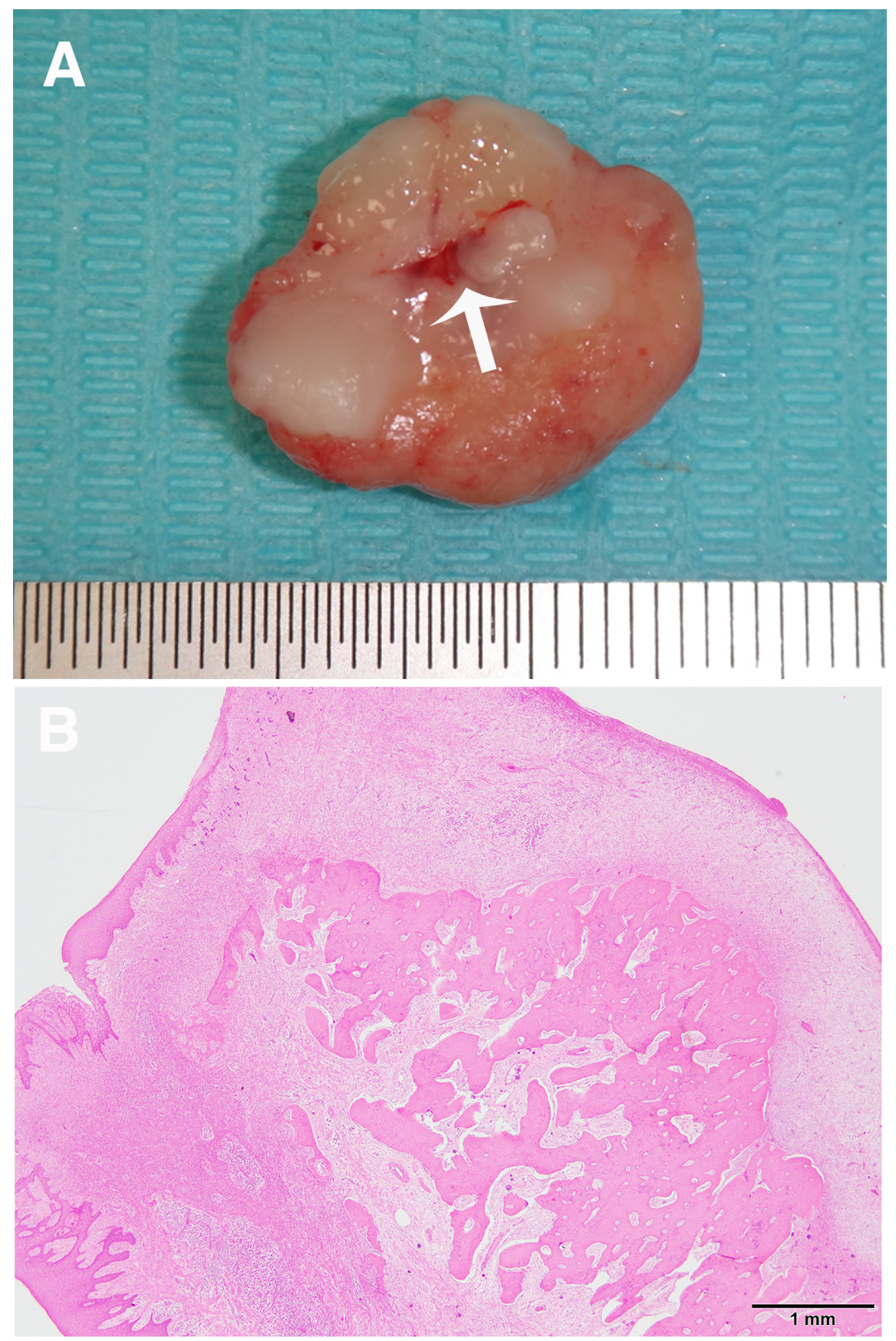

Figure 2 